\title{
De cerca medieval islámica a frente abaluartado: génesis y evolución del Frente de Tierra de Ceuta
}

From Medieval Islamic Wall to Bastioned Land Front: Genesis and evolution of the Land Front of Ceuta

\author{
Fernando Villada Paredes \\ Instituto de Estudios Ceutíes, Ceuta, Spain, fvillada@ceuta.es
}

\begin{abstract}
Ceuta is built on a peninsula at the southern shore of the Strait of Gibraltar. It's a strategic point for communications between the Mediterranean Sea and the Atlantic Ocean and between two continents: Europe and Africa. As Ceuta ships rule the Gibraltar Strait in Medieval and Modern Ages, main defensive efforts were tuned of to Land Front. Consequently, in 950 'Abd al-Rahman III built a new fence in order to protect the madina reusing Roman and Byzantine fortifications. Although repaired and enlarged by Almohads, Marinids, and Portuguese, these walls and towers protected the Land Front of Ceuta until the sixteenth century. But, at this moment, pirobalistic artillery development had made this defensive device obsolete and a new bastioned front, an early and outstanding example of the new Renaissance ideas for the defense of the cities, was built. Archival documents, cartographic sources, etc., let us follow the main lines of this evolution. Recently, an archaeological research project has added new data on how this evolution, from Medieval to Renaissance fortifications, took place.
\end{abstract}

Keywords: Bastion, Medieval and Modern Age fortress, Ceuta.

\section{Introducción}

Ceuta está edificada sobre una estrecha península situada en la orilla sur del estrecho de Gibraltar (Fig. 1). Esta estratégica posición, en un punto nodal para las comunicaciones entre Europa y África y entre el Mediterráneo y el Atlántico, es clave para comprender su devenir histórico. Explica además por qué su posesión fue ambicionada por cuántas potencias han tenido intereses en esta región y justifica los grandes esfuerzos realizados para su defensa.

En este contexto, dominar las aguas circundantes era fundamental tanto para su defensa como para garantizar los intercambios comerciales en los que se cimentó su prosperidad en la edad Media. También para asegurar el abastecimiento, decisivo tras la conquista portuguesa de 1415 que la dejó aislada de su hinterland.

\section{Nota histórica}

Las primeras noticias textuales de las fortificaciones ceutíes conservadas se remontan a mediados del siglo X cuando Justiniano I ordenó la conquista de Ceuta y el establecimiento en ella de una fortaleza, una reconstrucción de la fortaleza romana que los vándalos habían arruinado (Propopio, 2003, pp. 115-116).

Ya a mediados del siglo X el califa cordobés 'Abd al-Rahman III construyó una muralla en piedra, concluida por su hijo al-Hakam II, para que protegiera la medina. Esta iniciativa forma parte de un proyecto más amplio de fortificación de las costas del estrecho de Gibraltar frente a las incursiones fatimíes (Villada Paredes, Gurriarán Daza, 2013). 

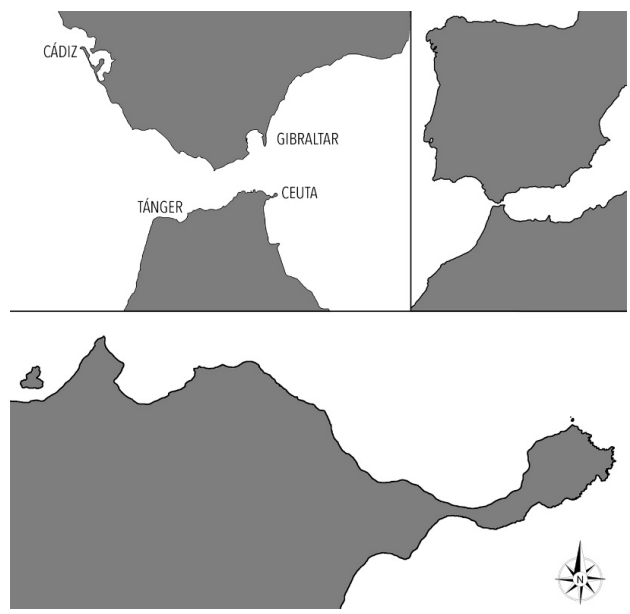

Fig. 1. Ceuta. Situación geográfica.

La mejor descripción de la muralla occidental de la medina ceutí es la de al-Bakrī. Estaba guarnecida por un recio lienzo con nueve torres. En la central se encontraba la principal puerta de la Ciudad. Delante de este muro se extendía otro más bajo, pero de suficiente altura para cubrir a un hombre. Al pie de la muralla se abría un foso largo y profundo atravesado por un puente. Este punto, indica, era suficientemente estrecho como para que se pudiese comunicar las aguas de las dos bahías si sus habitantes lo hubiesen deseado. Precisa además que ya los "antiguos" habían construido un foso con una longitud de dos tiros de flecha (al-Bakrī, 1913, pp. 202-203; sobre la fortificación omeya de Ceuta véase: Villada Paredes, Gurriarán Daza, 2013; Hita Ruiz, Suárez Padilla, Villada Paredes, 2008).

Bajo dominio almohade se construyó junto a esta puerta una gran calahorra. En el siglo XV alAnșarī dice que Bāb al-A'zam, llamada también la puerta nueva, era un monumento único (alAnșarī, 1982-1983, p. 145).

Las crónicas portuguesas narran varios episodios que transcurren en este lugar, citando que la puerta tenía varias estancias abovedadas que forman un trazado acodado, con dispositivos para el tiro vertical (Zurara, 1915, pp. 219-224).

A través de ella se salía a un pasillo entre el antemuro y el lienzo principal que conducía, a través de otra puerta abierta en el antemuro, hasta el puente que salvaba el foso.

Este antemuro, nombrado como la barreira por los portugueses, tuvo un papel fundamental para repeler los contraataques que iniciaron los musulmanes de forma inmediata (Villada, 2013).

Estas murallas islámicas sirvieron para defender la Ceuta portuguesa durante más de un siglo, aunque necesitaron de continuas reparaciones y mejoras que comenzaron inmediatamente después de la conquista: apenas vuelto el ejército a Portugal, Pedro de Meneses, el primer gobernador, "se dedicó a reparar quanto le pareció combeniente" (Correa, 1999, p. 123). Las reformas de las fortificaciones son confirmadas tanto por la presencia de diversos maestros de obras como por la llegada de hombres y materiales destinados a ellas (Villada, 2013).

A pesar de todo, las defensas se encontraban en bastante mal estado en algunos puntos. Además, eran demasiado extensas para las necesidades de la población y difíciles de defender dada la escasez de hombres de armas. Aunque el proceso comienza tras la conquista, en 1507 es D. Manuel I quien lo culmina: "Por los frentes de oriente y occidente y por lo más hondo y estrecho cortaron la ciudad" (Correa, 1999, p. 159). El occidental era ligeramente más largo que el oriental (243 m y $204 \mathrm{~m}$ respectivamente). Las puertas se mantuvieron en el mismo lugar en que estaban.

En 1511 Francisco Danzilho fue enviado a las plazas norteafricanas con 300 pedreiros. Lo que realizó se conoce por la medición efectuada por el maestre Boytac y por Luis Bastiam ( $\mathrm{Li}$ vro da medição das obras de Alcacer, Ceuta, Tanger e Arzilla) (Viterbo, 1899, vol. I, p. 272). Las obras se centraron en el baluarte y el puente levadizo de la puerta de la Almina, el Castelo, cuyo muro caído fue reconstruido más sólidamente (Dias, 2002, p. 37), y en las corachas (Correia, 2008, pp. 113-115). En 1522 los trabajos de Ceuta estaban a cargo de Rodrigo Redondo (Viterbo, 1898, v. III, pp. 413-414).

Pero todas estas obras, a pesar de las cantidades importantes a ellas destinadas, no consiguieron mejorar suficientemente el estado de defensa de Ceuta cuyas murallas en 1527 presentaban en opinión de Gomes da Silva de Vasconcelos, un estado lamentable. Esto motivó una nueva inspección llevada a cabo por Duarte Coelho al que acompañaron dos ingenieros, uno de ellos João de Castilho (Sousa, 1951-1954, vol. II, p. 85).

La situación continuaba siendo muy precaria años después. Así lo dice Nuno Alvarez en 1532 cuando, ante las noticias de un posible ataque de Barba Roja, señala que "hos muros d'ella [de 
Ceuta] estarem muy deneficados". La estancia de la coracha del sur, en que estaba la artillería, la de las bombardas gruesas sobre San Antonio y otra más debían hacerse mayores. También debían repararse las puertas del baluarte del sertão y las del muro nuevo, que estaban quebradas y en el suelo, así como el puente levadizo del mismo muro. Del mismo modo era urgente rehacer la garita de la torre de la campana y la de una de las corachas (SIHM, II, pp. 574-575).

Aunque el ataque turco jamás se produjo, lo que valió una severa advertencia del propio Rey al gobernador (SIHM, II, p. 581), esta amenaza se hizo cada vez más evidente: la pérdida en 1541 de Santa Cruz de Cabo de Gué (Agadir) supuso una clara advertencia de que la situación era muy delicada.

En ese mismo año una nueva carta del gobernador Alfonso de Noronha señalaba que Ceuta está "sem mamtimento nem munição, nenhũa pera artelharia, nem armas, e com muita parte dos muros pera cair, e portas como ha por muitas vezes sprevy a V.A.” (SIHM, III, p. 319).

Juan III, tras realizar consultas con los notables del reino, decide entonces modificar la estrategia portuguesa en el norte de África abandonando la mayor parte de las villas y ciudades. Únicamente Mazagán, Tánger y Ceuta quedarían bajo dominio luso y serían dotadas de nuevas defensas para garantizar su seguridad.

A Ceuta es enviado Benedito de Ravena, un ingeniero italiano al servicio de la Monarquía Hispana, acompañado por Miguel de Arruda. Este debía reclutar pedreros en la comarca de Évora y partir luego al Puerto de Santa María para esperar a Benedito. Llegados a Ceuta y revisado el estado de la plaza "ficaram muy espamtados de quão fraca le pareceo, e asi de quão mal rrepairada estaba ha artelharya" (SIHM, III, p. 434). Hasta tal punto era grave la situación que el Gobernador les conminó a que guardasen secreto de su evaluación.

El ingeniero debía valorar tres alternativas: realizar una nueva fortificación demoliendo lo existente, reformar lo que estaba hecho o, por último, reparar lo existente con el menor costo posible. De estas tres alternativas debía aportar dibujos y presupuesto (Moreira, 2001, p. 102). Tras redactar el proyecto fue enviado al rey que aprobó su ejecución.
El caso de la fortificación ceutí es singular pues se conserva el proyecto (Ricard, 1947), aunque no el plano que le servía de explicación, razón por la cual su interpretación ha sido a menudo bastante dispar (Dias, 2002; Correia, 2008; Ruiz Olivas, 2002; Matos, 2012).

La principal transformación tuvo lugar en el frente occidental. Allí se construyó un nuevo frente abaluartado con dos bastiones en cada extremo unidos por un recio lienzo y precedido por un foso de agua que ligase las bahías norte y sur. Además de su utilidad defensiva el nuevo foso serviría para el resguardo de embarcaciones.

El nuevo frente abaluartado acortó la longitud de las defensas con un nuevo atalho y la puerta principal mudó su ubicación a este, dónde era protegida por dos baluartes (Fig. 2).

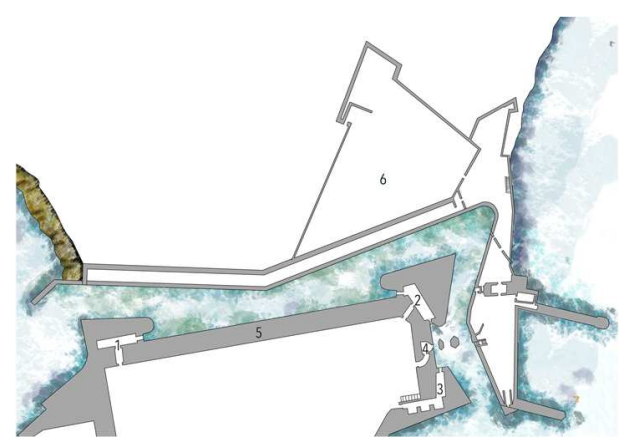

Fig. 2. El frente de tierra de Ceuta hacia 1690. 1) Baluarte coraza alta; 2) Baluarte torreón; 3) Baluarte mallorquines; 4) Puerta de la ciudadela; 5) Escarpa de la Muralla Real; 6) Obras exteriores.

Aprobado el proyecto, se iniciaron las obras dirigidas por Arruda. A pesar de que el Rey había ordenado seguir fielmente las disposiciones de Benedito de Ravena, fue necesario introducir algunas modificaciones. Así, por ejemplo, las bóvedas situadas al nivel del foso en cada baluarte no llegaron a construirse y la actuación prevista en la zona del albacar sufrió también alteraciones.

La obra comenzó por los baluartes a fin de asegurar la plaza. Para ello se solicitó al monarca el envío de vigas y maderas para hacer los terraplenes cuando se derribasen los muros (SHIM, III, pp. 434-435).

Los trabajos comenzaron inmediatamente pero pronto faltó cal para continuarlos (SHIM, III, p. 501) y en septiembre de 1542 la ciudad estaba falta de mantenimientos y municiones de guerra y sin muros para soportar un ataque de entidad 
(SHIM, III, p. 93). Se ordena entonces a João de Castilho, ante la amenaza de un ataque turco, traslade a Ceuta parte de los que trabajaban en la construcción de Mazagão por ser allí más necesarios (Moreira, 2001, p. 146).

Esta precariedad era denunciada nuevamente un año más tarde: Ceuta estaba sin pólvora, con poca artillería y sin armas ni municiones almacenadas "nem cousa com que nos mais possamos defender que com as mãos". Además, las obras que se realizaban en el albacar estaban en un momento crítico pues podía entrarse por este lugar sin precisar siquiera escalas (SIHM, IV, p. 131).

Sin embargo, en septiembre de 1548 la construcción estaba ya avanzaba y se trabajaba en la torre do çeitil y en la contraescarpa del foso, aunque ante la llegada del invierno no se podría abrir este para que pasasen las aguas hasta el año siguiente (SIHM, IV, pp. 295-296).

Ocho meses después, mayo de 1549 , a pesar de que aún el agua no entraba aún en el foso, el frente occidental estaba fuerte pero el muro sobre la puerta era aún muy bajo y las bandas de ambas bahías y la de la Almina tan débiles como siempre: ahora que el abastecimiento de cal era suficiente faltaba dinero (SIHM, IV, p. 329).

En agosto de ese mismo año comunicaba el gobernador que comenzaría la tarea de derribar las Algeciras, una fortificación mariní cercana a la Ciudad, aunque dudaba poder demolerla por completo dado el elevado coste que suponía (SIHM, IV, p. 359).

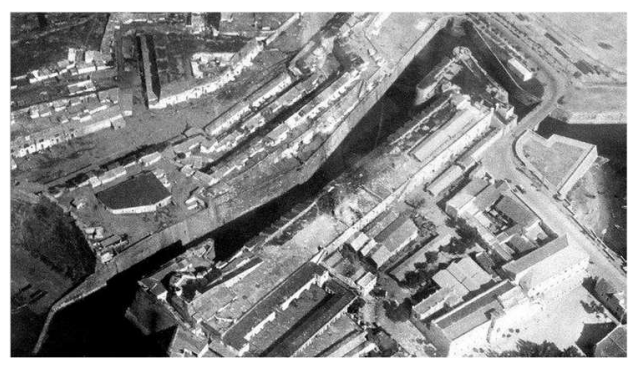

Fig. 3. El frente de tierra a principios del siglo XX.

Finalmente, en 1550 el foso ya había sido abierto a las aguas y las obras concluidas en su mayor parte.

La progresiva construcción de defensas exteriores, especialmente durante el Gran Cerco de $\mathrm{Mu}-$ lay Ismail (1694-1727), y la propia evolución del arte de fortificar hizo que la muralla real tuviese que ser modificada, incrementando su altura para permitir el tiro. Estos trabajos aparecen consignados en un plano de 1772 que muestra el recrecimiento (AGS, MPD, 64, 096).

También, para alojar las tropas, se construyen en el siglo XVIII una serie de bóvedas a prueba adosadas a la Muralla Real.

La ampliación de los límites fronterizos en 1860 restó importancia defensiva a estas murallas que propició la demolición de varias fortificaciones exteriores y el uso de las restantes para fines muy dispares (Fig. 3).

\section{El proyecto de investigación "Puerta Cali- fal" de Ceuta}

La identificación en 2002 de varios tramos de la cerca omeya y de una puerta de acceso a la Ciudad tras la escarpa de la Muralla Real propició el inicio de un proyecto de investigación que ha permitido, entre otras novedades, conocer con mayor precisión el modo en que se produjo la transformación de la cerca medieval en frente abaluartado. El proyecto ha tenido un carácter multidisciplinar combinado la investigación arqueológica con la lectura de paramentos, la caracterización de los materiales constructivos con identificación de los lugares de aprovisionamiento de materias primas y las pesquisas documentales. En el caso de las zonas no accesibles se han realizado estudios de refracción sónica y con cámaras térmicas para identificar posibles estructuras ocultas. Paralelamente se ha llevado a cabo una intensa labor de documentación con levantamiento de plantas y volúmenes con escáner 3D y fotogrametía de las fachadas exteriores.

Las actuaciones han sido llevadas a cabo en seis ámbitos distintos (Villada, 2012):

\section{- Baluarte del sur o de la coraza alta}

En el pasillo abovedado que conduce al interior de este baluarte ha sido identificado un lienzo de la cerca omeya, conservado hasta una altura aproximada de $12 \mathrm{~m}$. En la parte más alta tiene tres molduras paralelas que marcan el arranque del parapeto y merlatura original (Fig. 4).

Este muro, que parece apoyarse a su vez sobre otro más antiguo, quedó integrado en las fábricas renacentistas siendo visible con claridad únicamente en el pasillo descrito al quedar separado de las fábricas más recientes debido a la existencia de un dispositivo de tiro vertical. 
El muro califal fue finalmente horadado para permitir el paso al interior del baluarte.

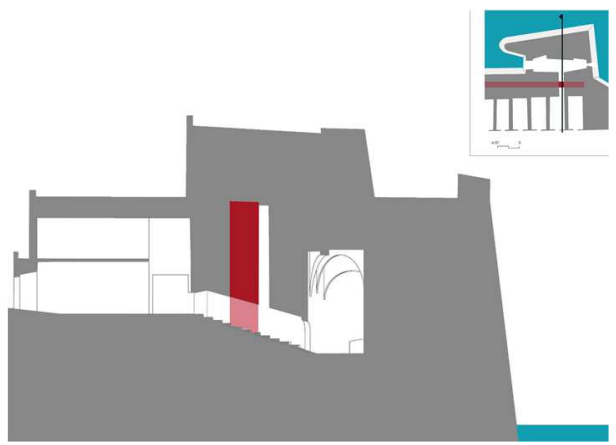

Fig. 4. Planta y sección del baluarte de la Coraza Alta. En rojo, lienzo califal.

- Escarpa de la muralla real

Un muro en cremallera, en el que se abre un vano con arco ultrasemicircular y doble alfiz, fue puesto al descubierto tras la realización de las excavaciones arqueológicas (2003-2014).

Conserva prácticamente toda su altura -también aquí encontramos una moldura que indica el arranque del parapeto-, aunque parte de los sillares han sido arrancados para ser reutilizados en otros lugares. A dos metros de este lienzo principal de la muralla califal, han sido identificados los vestigios muy arrasados de otro de menor entidad que corresponden al antemuro descrito por al-Bakrī.

Traspasado el vano de ingreso se llega a una habitación de planta cuadrangular y cubierta con bóveda de arista rebajada que conecta con una torre y otras estancias. Para su construcción se reaprovecharon estructuras defensivas tardo-antiguas (siglos VI-VII d.C.).

La puerta, que conserva parcialmente su decoración, fue colmatada parcialmente tras la erección del frente abaluartado.

Se conservan también una recia rampa de acceso a la cubierta, una atarjea de evacuación de pluviales y otra puerta en uso durante la construcción portuguesa, todas también cegadas tras la culminación de los trabajos (Fig. 5).

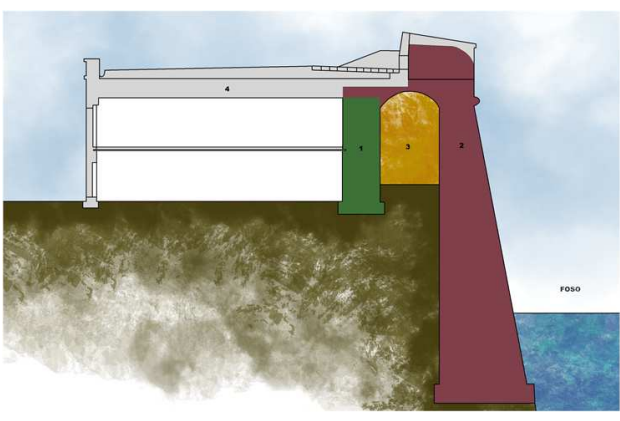

Fig. 5. Esquema constructivo de la Muralla Real. 1) Muralla califal (verde); 2) Muralla portuguesa (magenta); 3) Entulho portugués (ocre); 4) Reformas castellanas (gris).

\section{- Baluarte del torreón o de la bandera}

Las excavaciones arqueológicas (2014-2019) han permitido identificar una secuencia similar a la ya descrita: un lienzo omeya, que se levanta apoyado en estructuras defensivas precedentes (tardo-antiguas y romanas), queda embutido en las fábricas del baluarte y recortado para permitir la construcción del vano interior.

\section{- Baluarte de los mallorquines}

El frente norte de este baluarte integra otro lienzo de la cerca califal y los vestigios de una posible coracha. Esta corta el desarrollo del muro omeya y es amortizada por la construcción del baluarte por lo que debe ser fechada entre la segunda mitad del siglo X y el siglo XVI.

\section{- Cubierta Muralla Real}

Las excavaciones en varios puntos de la cubierta de la Muralla Real portuguesa han permitido documentar las reformas que en el periodo manuelino (principios del siglo XVI) se realizaron en la muralla omeya para adaptarlas al uso de la artillería pirobalística: la merlatura original fue sustituida por un parapeto más sólido que sirvió para proteger las bocas de fuego instaladas sobre la puerta califal. Del mismo modo han permitido identificar los merlones portugueses de sección curva sustituidos en el siglo XVIII cuando la cota fue elevada para permitir el fuego sobre posiciones enemigas una vez levantadas fortificaciones adelantadas.

- Bóvedas adosadas a la muralla real.

Han sido exhumadas estructuras de cronología dispar (romana, tardo-antigua, medieval y moderna) junto al frente amurallado. 


\section{Conclusiones}

El proyecto de investigación "Puerta Califal de Ceuta" ha permitido comprender con mayor detalle la génesis y evolución del amurallamiento del frente occidental de Ceuta (Fig. 6).

Los primeros datos sobre presencia humana en este lugar se remontan a 170000 años BP.

En torno al cambio de era se instala allí un centro de transformación de productos marinos que continúa en uso hasta al menos el siglo $\mathrm{V}$ y también un dispositivo defensivo (siglo III d.C.) localizado en el baluarte del Torreón, que se vio afectado por un evento de alta energía, un seísmo, entre los siglos III-V d.C. (Villada Paredes, Bernal Casasola, 2019).

Tras la conquista bizantina de Ceuta (533-534) se levanta una muralla cuyos vestigios son visibles en el baluarte del Torreón, la escarpa y el baluarte de la Coraza Alta (Villada Paredes, Bernal Casasola, 2019).

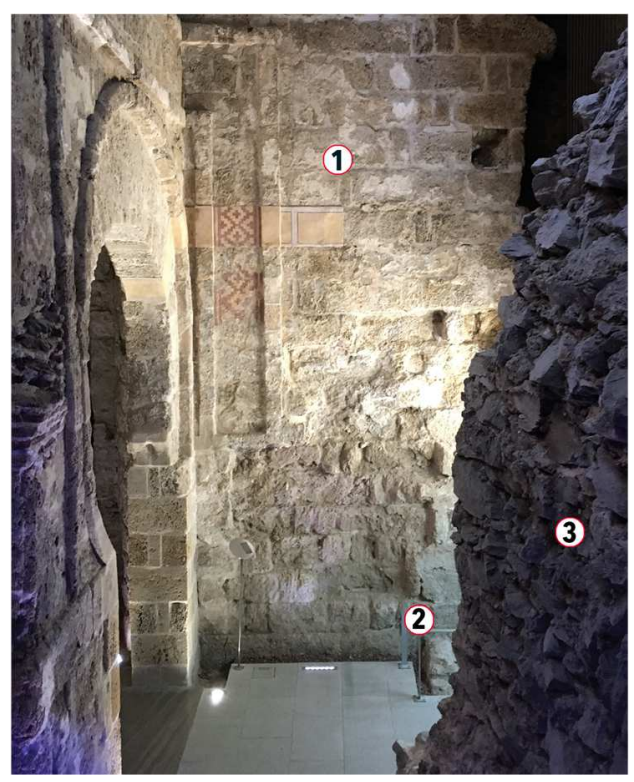

Fig. 6. Puerta califal musealizada. 1) lienzo califal; 2) antemuro califal; 3) muralla portuguesa.

La toma de Ceuta por los omeyas cordobeses (931) convierte la ciudad en un punto estratégico para la política norteafricana del Califato. Ello lleva a 'Abd al-Rahman III a iniciar la construcción de una nueva muralla de sillares de biocalcaretina que protege la medina, especialmente só- lida en su frente occidental. Los datos de la excavación arqueológica han permitido reconstruir su estructura básica: un lienzo principal reforzado por torres al que antecedente un antemuro de menor tamaño, lo que confirma los datos de al-Bakrī. En este frente occidental, de cara al continente, se levanta la puerta monumental de ingreso a la ciudad, ampliada y reforzada en los siglos XII-XIV.

En 1415 se produjo la toma de Ceuta por los portugueses y hasta 1541 fueron estas murallas medievales islámicas, reparadas y remozadas, las que protegían la población. El desarrollo de la artillería pirobalística hizo necesarias adaptaciones diversas (ensanchamiento de torres para permitir situar piezas de artillería, aperturas de troneras y refuerzo de los parapetos) que modificaron la fisonomía de la cerca, pero que acabarían siendo insuficientes ante el incremento del poder de ofensa de la artillería enemiga, especialmente cuando la amenaza turca se hizo más evidente (Cook, 1993 1994).

Así, en 1541, el monarca portugués decidió reestructurar las posesiones portuguesas en el norte de África abandonando la mayoría de las plazas lusitanas y llevando a cabo una profunda remodelación de las que quedaron en su poder, Tánger, Mazagán y Ceuta. Para ello contó con la colaboración de un ingeniero al servicio de la monarquía hispana, Benedito de Rávena, enviado para trazar un proyecto defensivo que incorporase los nuevos avances -frente abaluartado, tiro cruzado, etc.surgidos fundamentalmente en Italia.

Es este el primer ejemplo del uso de tales técnicas, que acabaran siendo usadas en los cuatro confines del planeta, fuera de Europa (Matos, 2016).

El diseño de Benedito de Ravena implicó la realización de un nuevo atalho y la construcción de un frente abaluartado en el frente más expuesto, el occidental, de la Ciudad. Se construyó una recia escarpa con baluartes en sus esquinas, se ensanchó el foso seco para permitir la comunicación de las aguas de las bahías sur y norte y se trasladó la puerta principal de acceso al lado norte, protegida por dos baluartes (el del Torreón y el de los Mallorquines). El terreno frente a este frente occidental terminó por ser despejado de estructuras precedentes (Correa, 1999, pp. 169-171), culminando un proceso iniciado tras la conquista lusitana, para evitar ataques por sorpresa.

La dificultad de una obra de tal magnitud en un contexto en el que los recursos eran muy escasos 
hizo necesario optimizar los recursos disponibles y el consiguiente aprovechamiento de estructuras precedentes. Así, el nuevo frente fue levantado unos metros adelantado respecto a las murallas medievales, reduciéndose el espacio entre ambas -la escarpa se levanta ataluzada- a medida que se ganaba altura. Para facilitar los trabajos de excavación del foso y de construcción del nuevo frente se dejó abierta una puerta "de obra" en la escarpa, posteriormente cegada y disimulada, se construyó una sólida rampa en el espacio entre ambas murallas para facilitar la subida de las piezas de artillería y de otros materiales pesados a la cubierta y se construyó una atarjea para la evacuación de las aguas de lluvia cuando la construcción se realiza a cielo abierto. Además, la excavación llevada a cabo para la ampliación del foso planteaba un problema logístico importante que fue solucionado al cegar el espacio entre murallas con estas tierras. Apisonadas y asentadas con capas de cal, este entulho no solo permitió ensanchar la escarpa con menor coste, sino que además confería a esta mayor capacidad para la absorción de impactos.

La obra, culminada hacia 1550, resultó exitosa y de hecho otras fortificaciones fueron construidas utilizando algunas de las soluciones empleadas en Ceuta, con casos tan significativos como la fortaleza de Diu (India), trazada según las crónicas siguiendo lo realizado en Ceuta.

El dispositivo diseñado por Benedito de Rávena supuso una alteración fundamental del tejido urbano preexistente y una completa reformulación del sistema defensivo de Ceuta que ha condicionado su urbanismo hasta nuestra época.
Nuevas reformas se sucedieron ya en época española (siglo XVIII): elevación de la cota de la escarpa para permitir el disparo sobre las fortificaciones exteriores, sustitución de suelos para impedir los estragos causados por el impacto de los proyectiles y reestructuración de la merlatura), construcción de un caballero para proteger la Ciudad de los disparos efectuados desde el Morro de la Viña y la edificación de bóvedas adosadas a la escarpa para albergar las tropas que permitían además reforzarla.

Las dificultades económicas que atravesó la Ciudad en los siglos XVIII y XIX unidas a las amenazas que sobre ella se ceñían impidió afortunadamente llevar a cabo los proyectos de demolición que se elaboraron y han permitido sean conservados estos baluartes y lienzos.

El proyecto de investigación desarrollado en el frente occidental de la fortificación ceutí ha permitido, gracias a la aportación de la arqueología, profundizar en su génesis y evolución, descifrando algunas claves esenciales para comprender este palimpsesto edilicio que son las murallas ceutíes, un excepcional ejemplo del "arte de la defensa" a través de los últimos dos milenios (Fig. 7).

\section{Abreviaturas}

AGS: Archivo General de Simancas SIHM: Les Sources Inédites de 1’Histoire du Maroc.

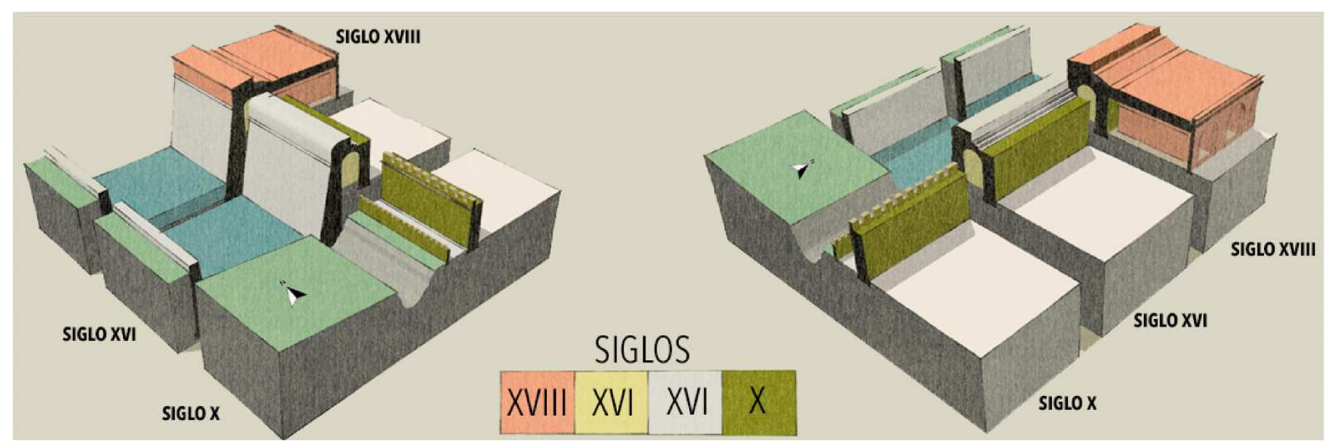

Fig. 7. Esquema evolutivo de la Muralla Real de Ceuta. 


\section{Bibliography}

Al-Anșarī. (1982-1983). "La physionomie monumentale de Ceuta: un hommage nostalgique a la ville par un de ses fils, Muḥammad b. al-Qāsim al- Anșar̄̄”, Ihtișār al-aḥbār trad., Hespéris-Tamuda, XX-XXI, pp. 113-162.

Al-Bakrī. (1913). Description de l'Afrique septentrionale, Typographie Adolphe Jourdan, Alger.

Cook, W.F.Jr. (1993). "Warfare and Firearms in Fifteenth Century Morocco, 1400-1492", War and Society, 11, pp. 25-40.

Cook, W.F.Jr. (1994). The Hundred Years War for Morocco: Gunpowder and the Military Revolution in the Early Modern Muslim World, Westview Press, Boulder.

Correa da Franca, A. (1999). Historia de la mui noble y fidelíssima ciudad de Ceuta, Ciudad Autónoma, Ceuta.

Correia, J. (2008). Implantação da Cidade Portuguesa no Norte de África. Da tomada de Ceuta a meados do século $X V I$, FAUP, Porto.

Dias, P. (2002). A Arquitectura dos Portugueses em Marrocos 1415-1769, Livraria Minerva, Lisboa.

Hita Ruiz, J.M.; Suárez Padilla, J.; Villada Paredes, F. (2008). "Ceuta, puerta de al Andalus. Una relectura de la historia de Ceuta desde la conquista árabe hasta la fitna a partir de los datos arqueológicos”, Cuadernos de Madinat alZahra, 6, pp. 11-52.

Matos, J.B. (2012). Do mar contra terra. Mazagão, Ceuta e Diu, primeiras fortificações abaluartadas da expansão portuguesa. Estudo arquitectónico (tese de doutouramento), Universidad de Sevilla, Sevilla.

Matos, J.B. (2016). "First Portuguese Bastioned Fortress in North Africa", in FORTMED 2016. Defensive Architecture of the Mediterranean. XV to XVIII centuries, vol. III, pp. 333-340.

Moreira, R. (2001). A construção do Mazagão- Cartas inéditas 1451-1542, IPPAR, Lisboa.

Periago Lorente, M. trad. (2003). "Procopio de Cesarea: Los edificios", Estudios Orientales, 7.

Ricard, R. (1947). "Documento portugués de 1541 sobre las fortificaciones de Ceuta", Al-Andalus, 12-1, pp. 43-48.

Ruiz Oliva, J.A. (2002). Fortificaciones militares de Ceuta: siglos XVI-XVIII, Instituto de Estudios Ceutíes, Ceuta.

SIHM. (1934-1953). Les Sources Inédites de l'Histoire du Maroc. Première série. Dynastie Sa'adienne. Archives et bibliothèques de Portugal, Paul Geuthner, Paris, 5 toms.

Sousa, F.L. de. (1951-54). Anais de D. João III, Livraria Sá da Costa, Lisboa.

Villada Paredes, F. (2012). "Excavaciones arqueológicas en la Muralla Real de Ceuta. Persistencia y rupturas en las murallas ceutíes durante el periodo portugués (1415-1668)", in Velhos e Novos Mundos. Congresso Internacional de Arqueologia Moderna, pp. 375-384.

Villada Paredes, F. (2013). "De huma parte cercados do mar, e da outra dos imigos... Notas sobre a defesa de Ceuta desde 1415 até ao reinado de D. Manuel I (1415-1521)", Artis, 1, pp. 9-19.

Villada Paredes, F.; Gurriarán Daza, P. (2013). "Recientes investigaciones sobre las fortificaciones del califato omeya en el Estrecho de Gibraltar (Algeciras, Ceuta, Tánger y Tarifa)", in Fortificações e Território na Península Ibérica e no Magreb (séculos VI a XVI). Óbidos 10-14 de Novembro de 2010, Colibrí/Campo Arqueológico de Mértola Ed., Lisboa.

Villada Paredes, F.; Bernal Casasola, D. (2019). "Del Istmo a las Murallas Reales. Un desafío para la arqueología preislámica de Septem (ss. I-VII d.C.)”, Antiquités Africaines, 55, pp. 185-213.

Viterbo, S. coord. (1899-1904). Diccionario historico e documental dos Architectos, Engenheiros e Constructores portugueses ou a serviço de Portugal, Imprensa Nacional, Lisboa.

Zurara, G.E. de. (1915). Crónica da Tomada de Ceuta por el Rei D. João I, Academia das Ciências, Lisboa. 